\title{
月三年七十二治 明
}

\begin{tabular}{|c|c|c|c|c|c|c|c|c|c|c|c|c|c|c|c|c|c|}
\hline & 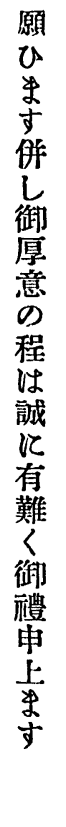 & 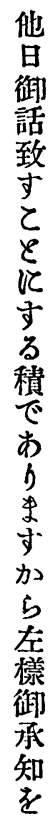 & 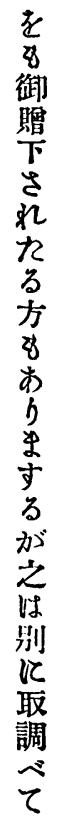 & 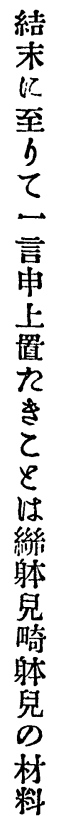 & 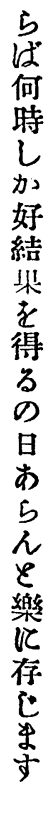 & 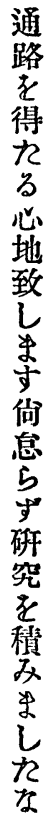 & 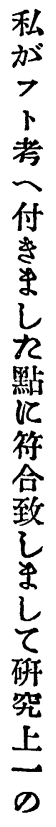 & 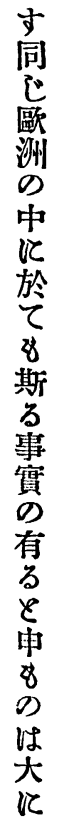 & 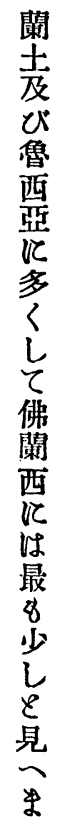 & 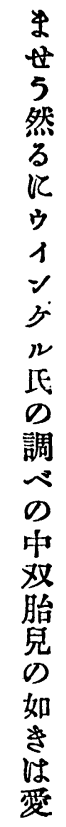 & 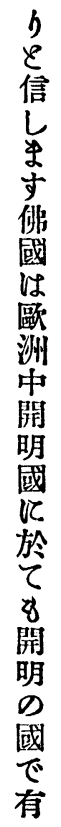 & 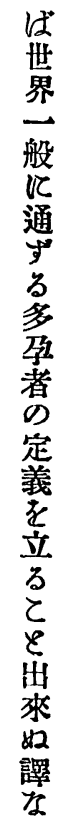 & 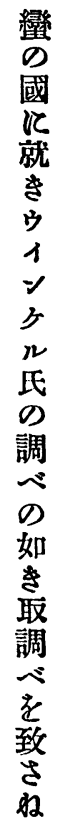 & 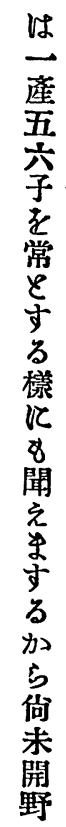 & 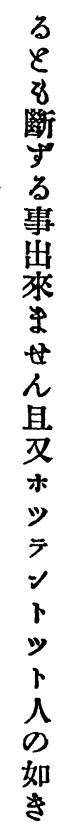 & 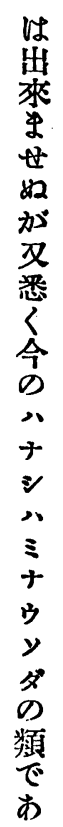 & 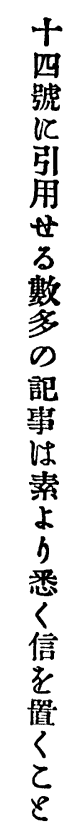 \\
\hline 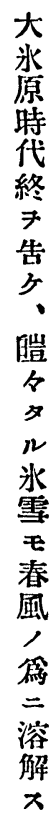 & 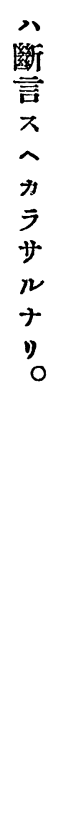 & 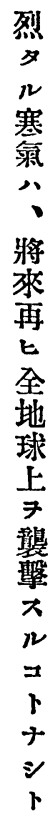 & 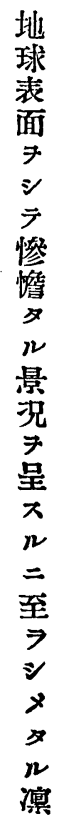 & 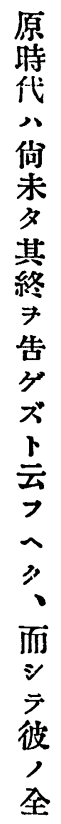 & 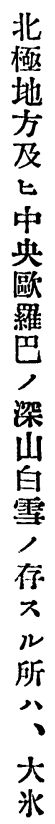 & 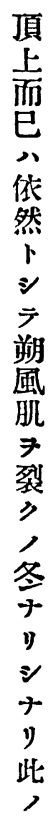 & 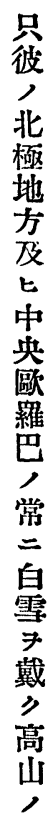 & 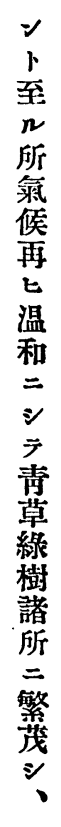 & 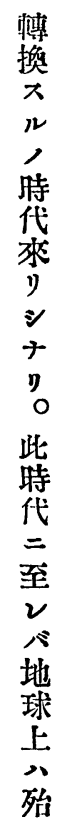 & 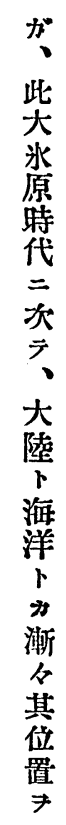 & 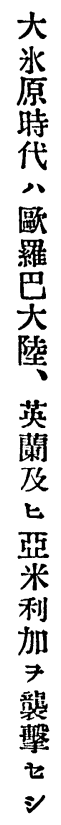 & $\begin{array}{c}\text { 第 } \\
\text { 音 } \\
\text { 原 } \\
\text { 生 } \\
\text { 活 } \\
\text { 有 } \\
\text { 樣 } \\
\text { 知 } \\
\text { 几 } \\
\text { 法 }\end{array}$ & $\begin{array}{l}\text { 抄 } \\
\text { 譯 } \\
\text { 者 } \\
\text { 佐 } \\
\text { 藤 }\end{array}$ & $\begin{array}{c}\text { 原 } \\
\text { 著 } \\
\text { 者 } \\
\text { ダ } \\
\text { ン } \\
\text { が } \\
\text { ア } \\
\text { । } \\
\text { ス }\end{array}$ & $\begin{array}{c}\bigcirc \\
\text { 初考 } \\
\text { 尘古 } \\
\text { 原 } \\
\text { 会 } \\
\text { 物 } \\
\text { 㽬 }\end{array}$ & & 椎 \\
\hline
\end{tabular}


號六十九第詰雑會學類人京東

\begin{tabular}{|c|c|c|c|c|c|c|c|c|c|c|c|c|c|c|c|c|c|}
\hline 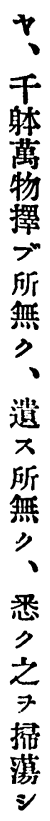 & 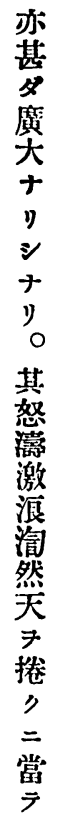 & 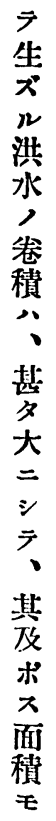 & 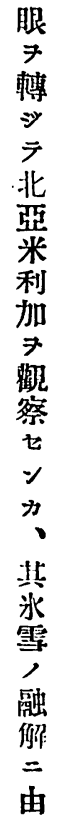 & 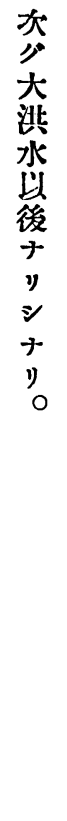 & 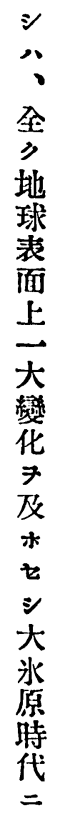 & 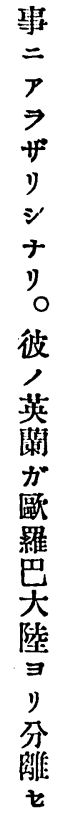 & 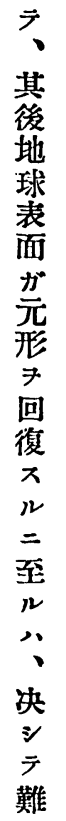 & 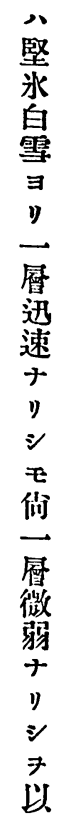 & 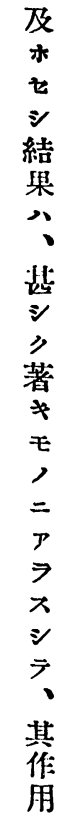 & 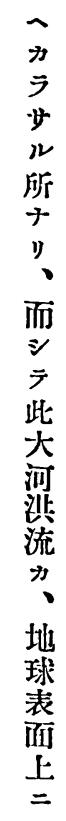 & 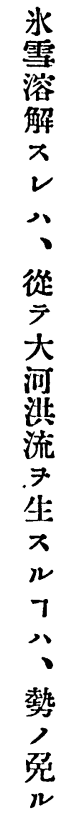 & 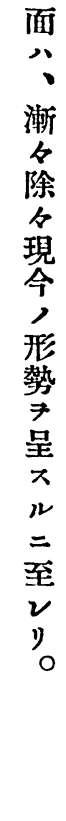 & 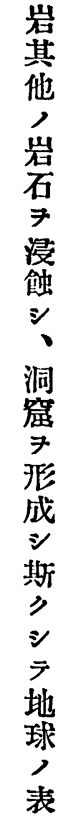 & 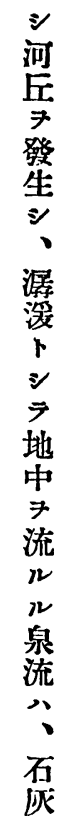 & 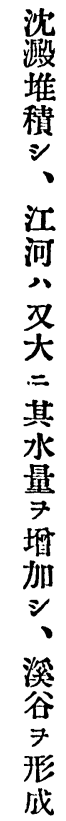 & 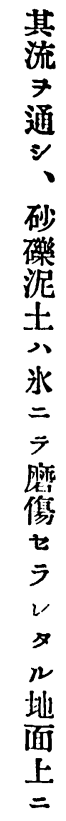 & 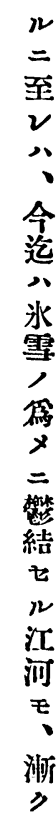 \\
\hline 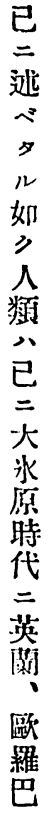 & 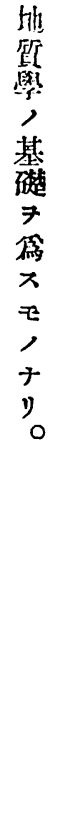 & 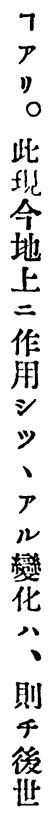 & 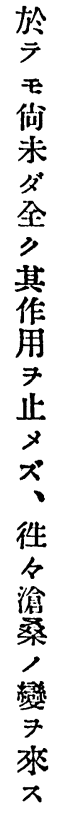 & 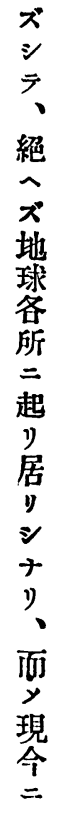 & 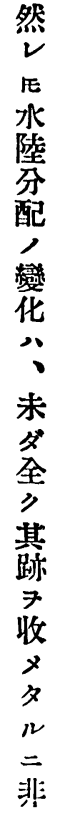 & 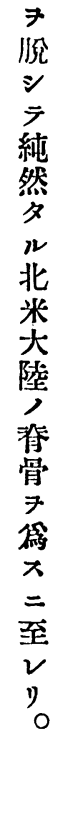 & 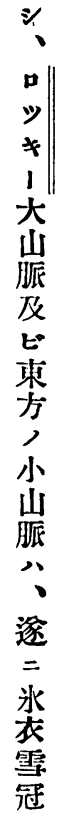 & 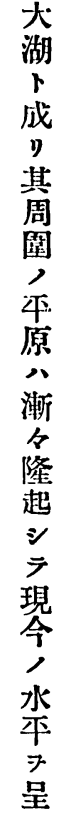 & 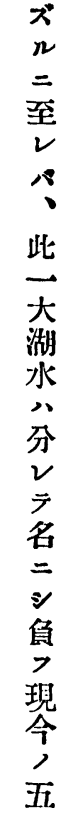 & 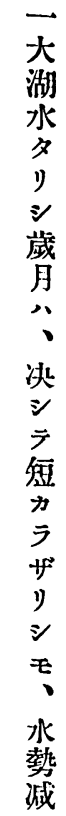 & 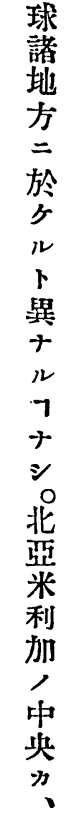 & 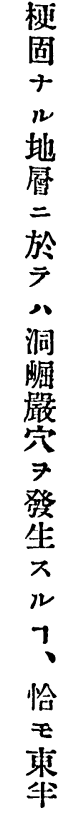 & 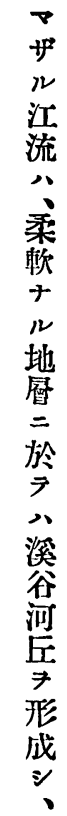 & 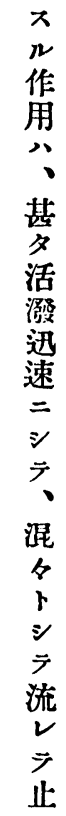 & 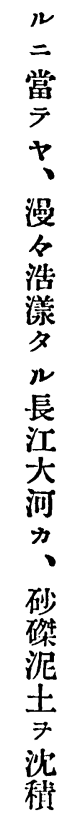 & 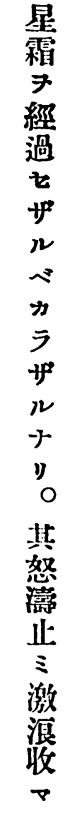 & 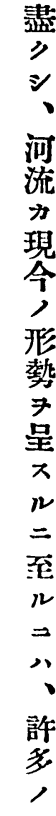 \\
\hline
\end{tabular}


月三年七十二治 明

如卜 ○ 们 $三$ 後 冬

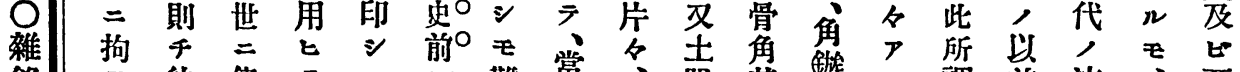

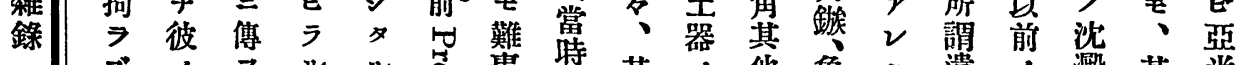

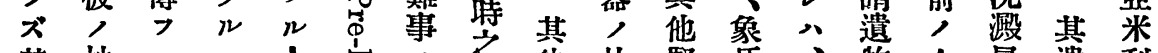
其地水人它

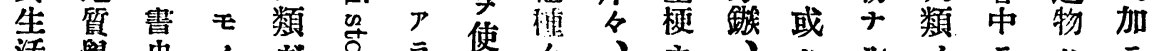

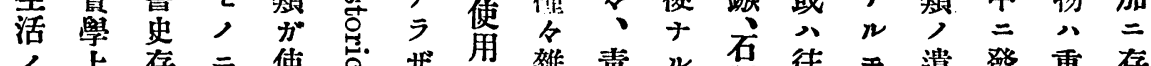

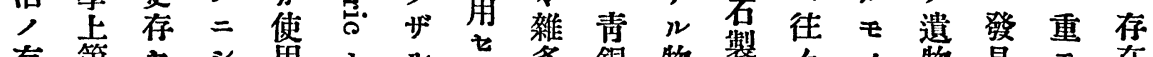

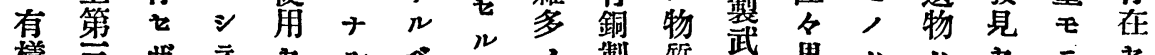

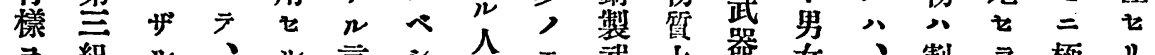
$\exists$ 紀 $n$ 、

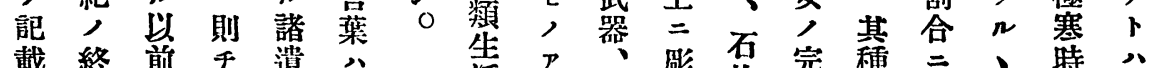

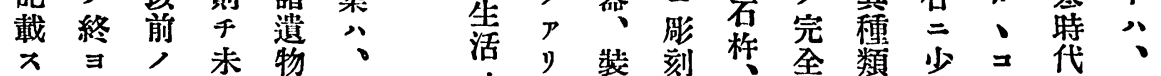

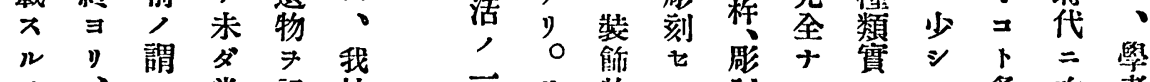

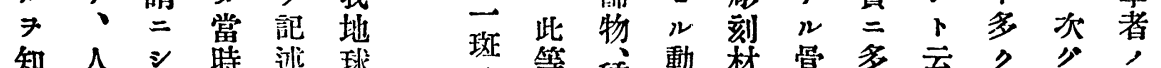
知人 $三$ 特速琲斑等種動㷊骨多云》分,

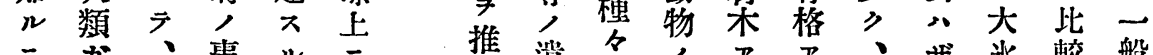

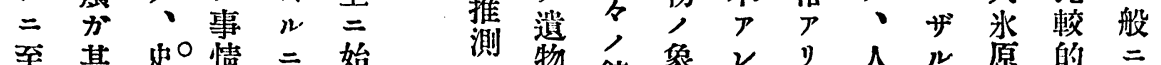

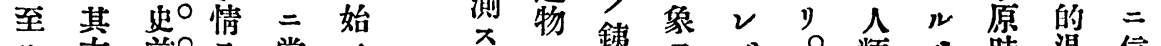
方 前 $¥$ 當 メ ル 沦法時能 、

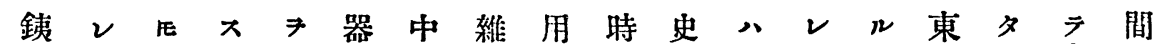
器》、ル 混特 時 0 漸年合代 $モ$ 曰 代第各代

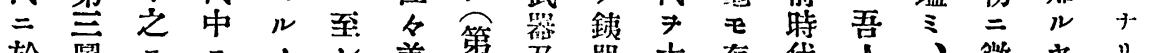

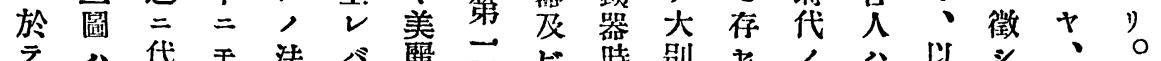

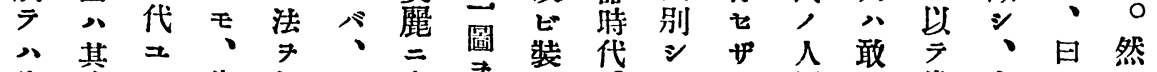

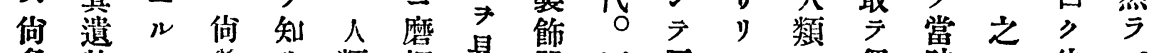

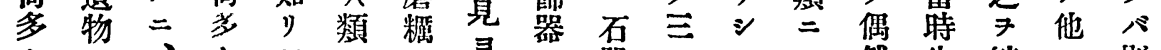
》, ‘

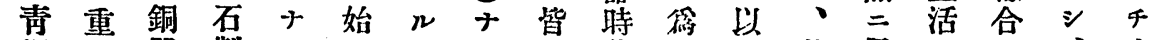
銅ナ器製りメモル石代

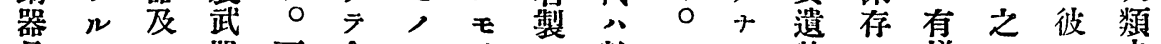

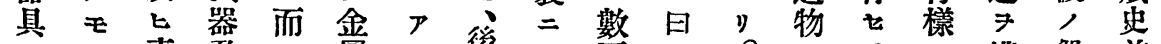

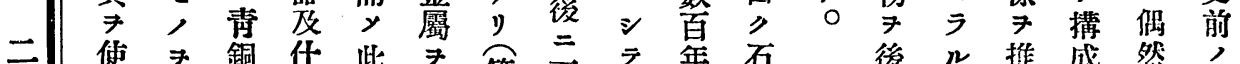

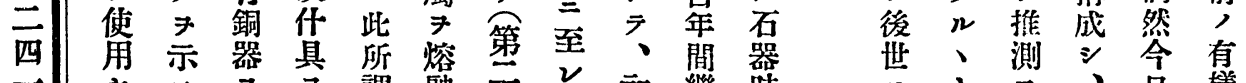

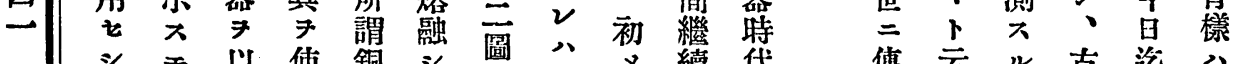

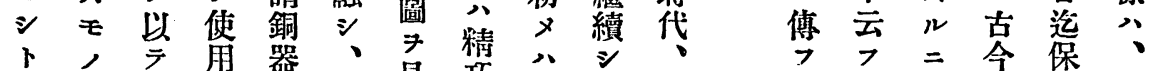

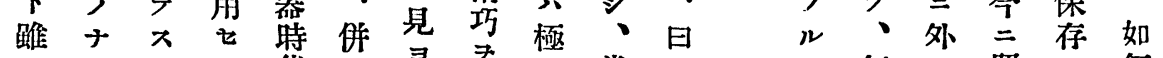

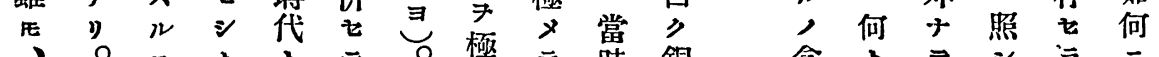
人 0 至踓䊈之 
號六十九第誌雑會學類人京東

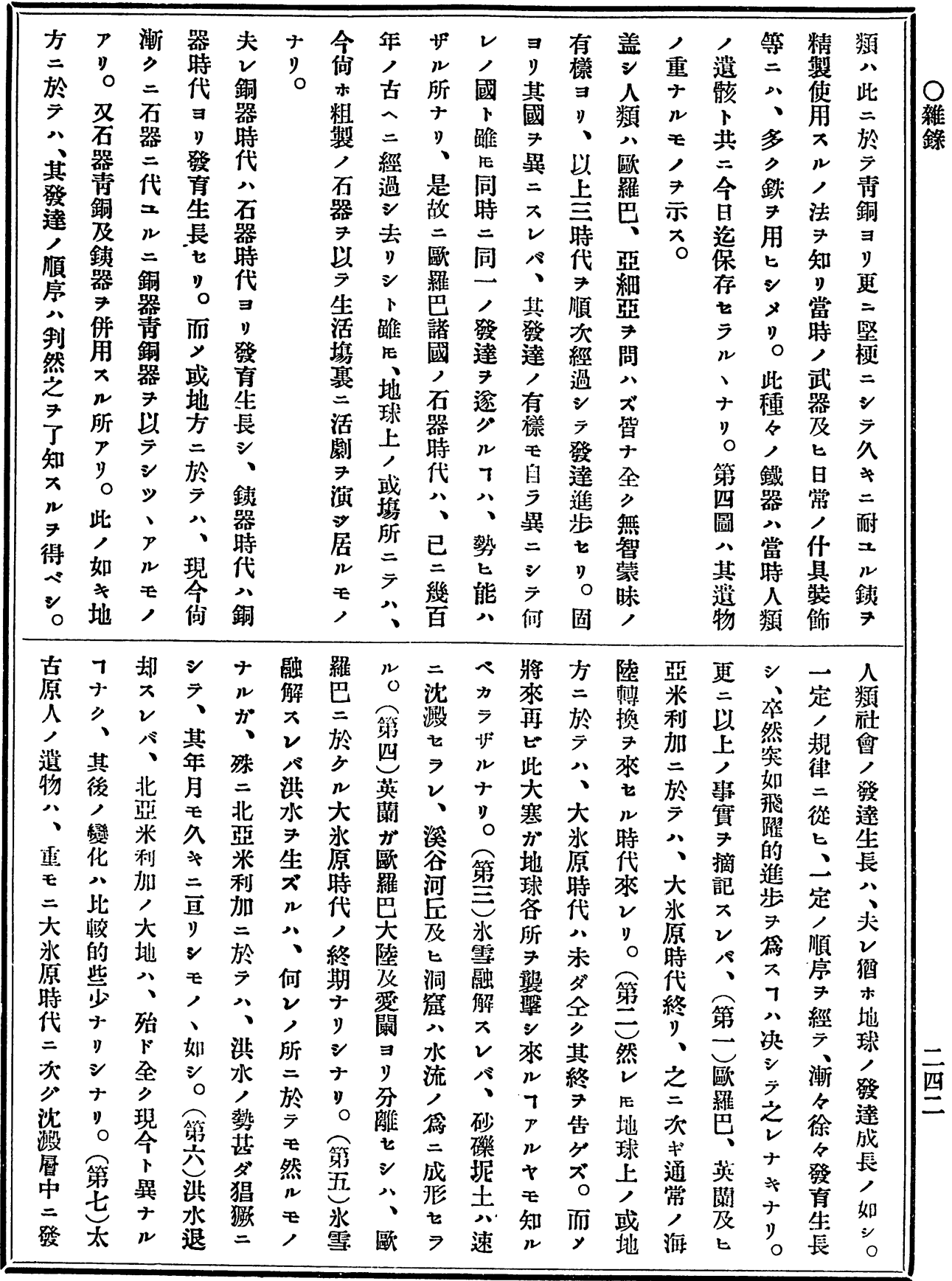




\section{月三年七十二治 明}

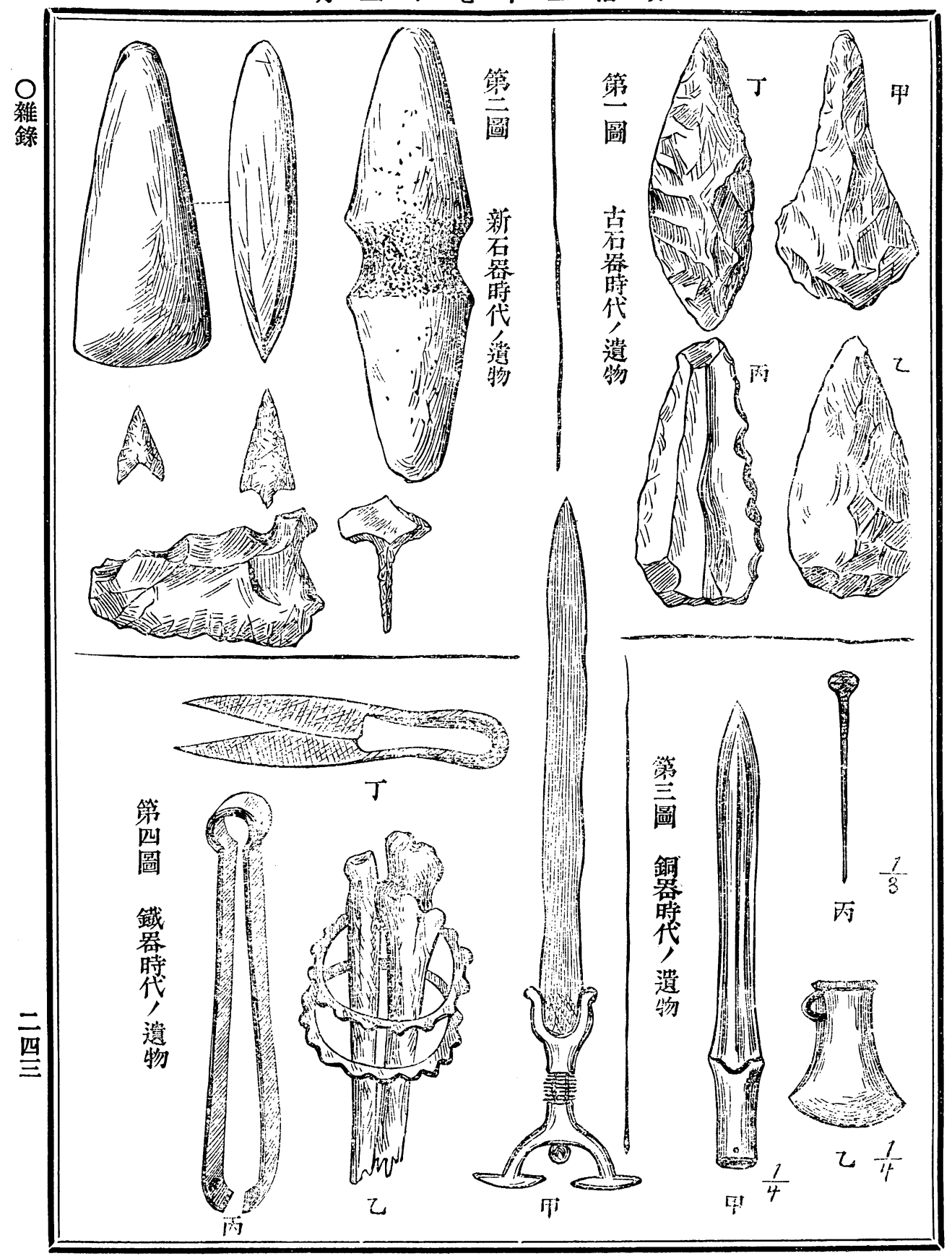


號六十九第詰雜會學頑人京東

存二ダ 次當器青混りテ十大ス只片爷女是 在数 $ン$ 發 特特銅合 0 -

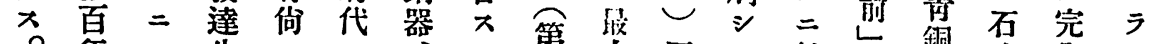

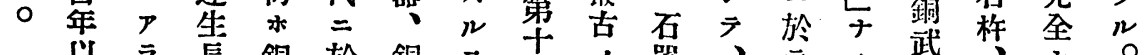
以

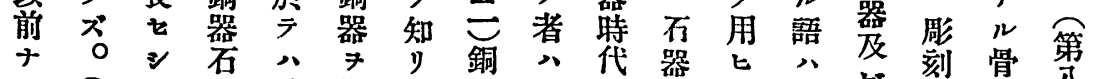
$y$ 第

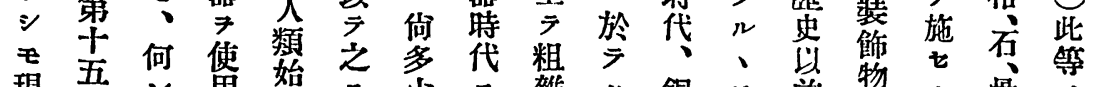

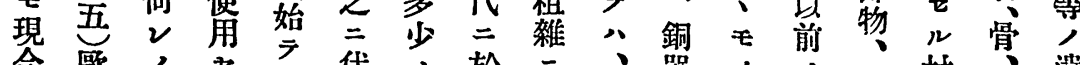

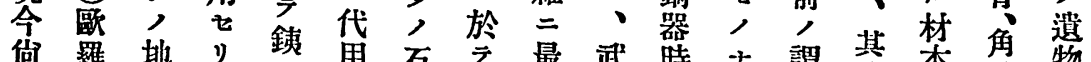
鹪羅劦

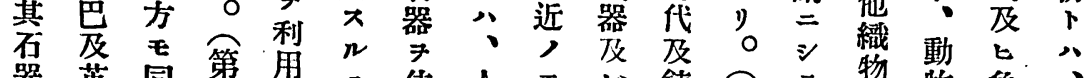
器英同第用二使人モ銕第 人國特四云至角栭, 装器第、破, 牙重 ₹ 石同五, v 七 始 $心$ 飾 時

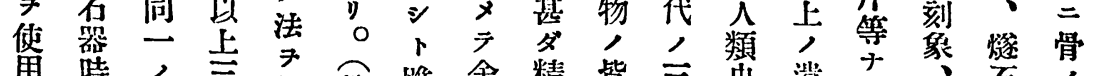

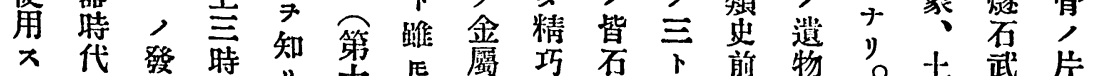
人

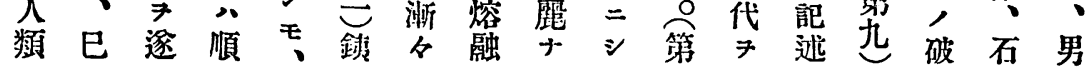

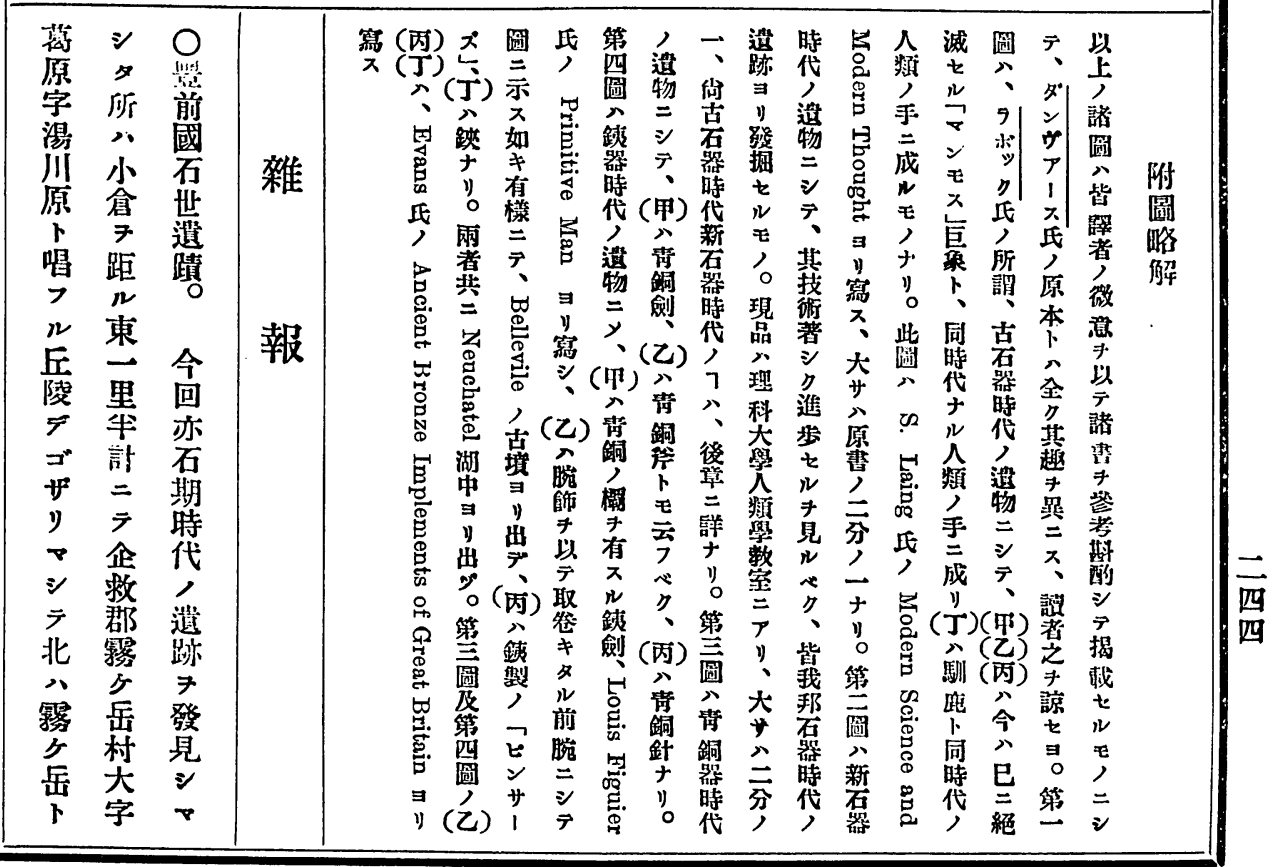

